Review Articles

\title{
A grammar of Kolyma Yukaghir
}

\author{
IRINA NIKOLAEVA
}

Elena Maslova, A Grammar of Kolyma Yukaghir. (Mouton Grammar Library, 27.) Berlin: Mouton de Gruyter, 2003, xviii + 609 pages, ISBN 3-11-017527-4, EUR 148.

\section{General}

Kolyma Yukaghir and Tundra Yukaghir are closely related languages spoken in the north-eastern part of Russia. Kolyma Yukaghir at present has about 40 speakers. The language is not entirely undescribed: Jochelson (1905) and especially Krejnovič $(1979,1982)$ are useful accounts of morphology and give basic phonological and syntactic information, while Nyikolajeva (2000) is a short overview of Yukaghir grammar in historical perspective. There are a number of articles by various authors focusing on particular grammatical points. Several folklore text collections have been published (Jochelson 1898, 1900; Nikolaeva (ed.) 1989, 1997; Maslova 2002). These works provide essential facts about the language. However, most of them are written in Russian or Hungarian and use terminology and representational conventions that do not always correspond to modern scholarly practice, with examples presented less than transparently, often lacking morpheme-by-morpheme glossing. Most importantly, previous descriptions have many gaps by modern standards and for the most part ignore syntax. Described incompletely, idiosyncratically, and somewhat inaccessibly, Yukaghir grammar has played little or no role in considerations of modern theoretical linguists and typologists.

Elena Maslova's new grammar will certainly remedy this situation as it is the only lengthy book on Yukaghir easily accessible for the international linguistic audience. It is written in English and provides a thoroughly organized and conventionally structured description reflecting the standards of modern linguistic scholarship. The presentation of the data is transparent and the discussion is clear. The description is intended to be comprehensive, i.e., to cover 
all major aspects of the language. The grammar offers a thoughtful treatment of grammatical topics that had not been adequately addressed before or been ignored entirely. The book is richly exemplified and is therefore valuable as a timeless piece of documentation of this highly endangered and understudied language. A useful feature of the book is that examples are clearly marked either as elicited or as obtained from natural discourse, with preference given to the latter. The description is based on materials from Maslova's own fieldwork, as well as on data from a published text collection. ${ }^{1}$

The book contains a grammatical description, a 15-page word list of core vocabulary and words occurring in the cited examples, a six page list of nonproductive suffixes of verbal derivation, 19 pages of analyzed texts, a list of references, and a subject index. The first two chapters offer the basic facts about the language and its speakers, including population figures, geographical location, the sociolinguistic situation, language contacts, and the relationship between Kolyma and Tundra Yukaghir, together with relevant references. ${ }^{2}$ As is emphasized on p. 28, the grammar deviates from the previous tradition in that it treats the Kolyma and Tundra varieties of Yukaghir as two closely related languages rather than dialects of a single language, a choice which is certainly justifiable but ultimately dependent on the criteria chosen. The first chapter also presents a short overview of Kolyma Yukaghir grammar and describes the purpose and the structure of the book, emphasizing that the grammatical description combines the "form-to-function" and "function-to-form" approaches. The descriptive chapters are organized around general semantic categories such as "Aspect" or "Tense and Mood", while the internal structure of each section is determined by grammatical distinctions expressed in Yukaghir. This certainly ensures a useful balance between widely assumed descriptive concepts and language-particular phenomena.

The grammatical description starts with Chapter 3, which briefly deals with phonology and covers such topics as phonemic inventory, syllable structure, vowel harmony, some phonological and morphophonemic alternations, and word stress. Chapter 4 introduces the Yukaghir parts of speech and the inflectional paradigms associated with each of them. Two major parts of speech, nouns and verbs, are fairly easily distinguishable by inflectional criteria. Nominal inflection comprises Plural, Possessive (in the 3rd person), and case suf-

1. Most of the data comes from Vasilij Šalugin, who was the principal language consultant and the narrator of most of the texts analyzed in the grammar (from Nikolaeva (ed.) 1989). Sadly, this talented man passed away in 2002.

2. However, some relevant references are missing. For example, in the discussion of the genetic affiliation of Yukaghir on p. 1 the most recent and comprehensive book on the topic (Fortescue 1998 ) is not mentioned. There is no mention of publications employing the Yukaghir writing system, in particular the school primer (Spiridonov \& Nikolaeva 1993). 
fixes, in that order. In finite verbal inflection the suffixes are ordered as follows: mood - number - tense - person. Importantly, property words constitute a subclass of verbs having the full finite paradigm and most of the non-finite forms. Thus, "the most typologically important feature of the Yukaghir part-of-speech system is the absence of adjectives" (p. 61; but see Section 4 below).

Chapter 5 outlines nominal morphology. An interesting feature of Plural marking is that in the context of the Possessive affix it can signify either the plurality of the entity denoted by the host noun, or of the entity cross-referenced by the Possessive marker, or both. Thus, num $\phi$-pe-gi [house-PL-POss] can mean 'his/her houses', 'their house', or 'their houses' (p. 86). ${ }^{3}$ It should be noted that the same is observed in the neighboring language Yakut (Stachowski \& Menz 1998: 422), so apparently we are dealing with an areal feature.

The focus of Chapter 6 is verbal categories. The finite verbal forms are organized around two parameters: illocutionary force and the expression of grammatical Focus. Non-assertive force is expressed by means of Imperative, Prohibitive, and Interrogative. The assertive (Indicative) paradigm has four subparadigms: intransitive Main forms, transitive Main forms, intransitive SubjectFocus forms, and transitive Object-Focus forms. The finite verb agrees in person and number with the subject, but in Subject-Focus and Object-Focus subparadigms agreement is morphologically meager. The only obligatorily expressed tense distinction is Future vs. non-Future. The distinction between past and non-past is achieved by aspectual affixes in combination with the lexical meaning of the verb.

Chapter 7 deals with the morphology of closed classes. The syntactic part of the grammar begins with Chapter 8 concentrating on the noun phrase and the postpositional phrase. It describes possessive constructions, modification, and NP coordination. Yukaghir has three strategies of NP conjunction - comitative, asyndeton, and conjunctional - but the latter is infrequent. As in many languages where the conjunction 'and' is absent or marginal, the primary strategy employs the Comitative case, either on one conjunct or on both.

Chapter 9 provides information on key aspects of clausal syntax. Yukaghir is known to be typologically interesting in that it exhibits a close association between the case marking of core participants and their information structure status (Comrie 1992, Fortescue 1996, Maslova 1997). The primary participant in the finite intransitive clause and the secondary participant in the finite transitive clause receive alternative grammatical encodings depending on

3. In this review article I have followed Maslova's transcriptional conventions. In particular, the letter $h$ stands for a voiced uvular fricative and $d$ ' for a voiced palatal affricate. Yet there are two important deviations: I indicate long vowels with a colon rather than a macron and do not transcribe long mid vowels as diphthongs, as Maslova sometimes does. I also use Maslova's conventions for glosses, although some minor deviations are possible. 
their Focus/non-Focus status. In intransitive clauses Yukaghir shows a special "Focus-oriented" case of split-intransitivity: the non-Focus primary participant takes the Nominative (1a), while the Focus primary participant takes the Predicative (1b).

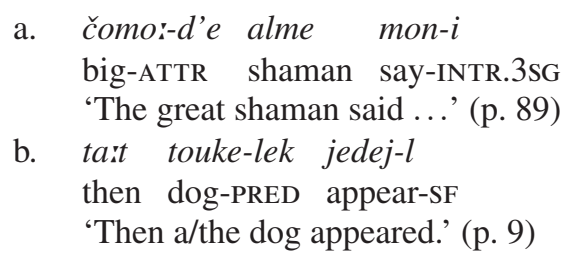

In transitive clauses the Focus object is encoded by the Predicative (2a). The marking of the non-Focus object depends on the deictic status of the primary participant: it takes the Nominative if the primary participant is 1 st or 2nd person (2b), or the Accusative/Instrumental if it is 3rd person (2c). In all three cases the primary participant stands in the Nominative.

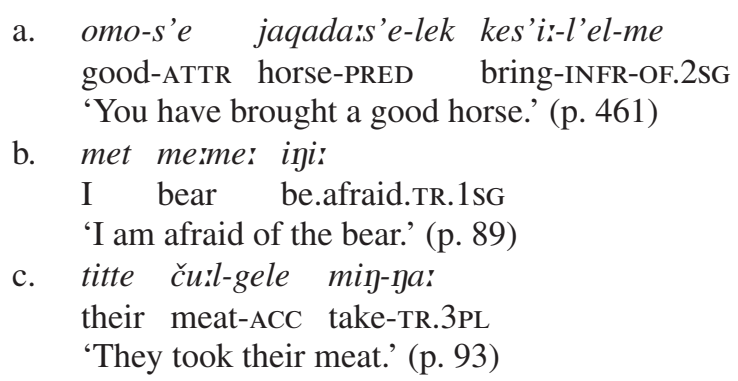

So Focus marking works on an ergative basis, cf. (1b) and (2a). This mechanism can be viewed as a result of the close association of the Focus function with the primary participant of the intransitive verb, on the one hand, and the secondary participant of the transitive verb, on the other hand, as also attested in other languages (e.g., Du Bois 1987). What makes Yukaghir typologically remarkable is that this association is highly grammaticalized.

The question that arises in connection with this system is that of grammatical relations, namely, which grammatical units (if any) can be associated with the syntactic functions of the subject and the direct object. The chapter thoroughly argues that although the non-Focus primary participant of intransitive clauses demonstrates split case marking, in both cases it behaves as a grammatical subject. Thus, Kolyma Yukaghir can be called a "subject-prominent" language. Subjecthood is defined on participant roles, without regard for their surface expression (case marking). Similarly, direct object properties are associated with the secondary participant of transitive clauses, independently of its case. 
Chapter 10 outlines the phenomenon of clause chaining, while Chapter 11 covers in turn three major types of non-finite subordinating constructions: complement clauses, relative clauses, and adverbial clauses. Sentential complementation is mostly expressed by clausal nominalizations. Various types of sentential subjects and objects are fairly typical from the crosslinguistic point of view. Relative clauses are built by means of attributive forms of verbs and deverbal nominals (the Action Nominal and Result Nominal). The following grammatical functions can be relativized: subject, direct object, spatial or temporal locative, and possessor of the intransitive subject. This distribution is typologically interesting, as it involves the highest and the lowest ranks of the Noun Accessibility Hierarchy (Keenan \& Comrie 1977). Finally, adverbal clauses are headed by deverbal nominals with various case and postpositional markings.

Chapter 12 addresses nominal predicates. It also deals more thoroughly with Focus constructions, since the morphology employed in Focus marking shows a similarity to cleft and cleft-like structures. As can be seen from (1) and (2) above, if a clause is marked for a grammatical Focus by means of the Predicative case, the verb form is selected from the Subject-Focus or ObjectFocus sub-paradigms. Otherwise the verb form is selected from the Main subparadigm. The Subject-Focus sub-paradigm is morphologically based on the Action Nominal, whereas the Object-Focus paradigm is based on the Passive attributive form. So the Focus NP takes Predicative marking which is also employed for nominal predicates, while the verbal forms are identical to those employed for relativization. In contrast to her own previous analysis of Focus constructions as a sort of biclausal clefts (Maslova 1997: 465-466), Maslova comes to the well-argued conclusion that the Focus NP is a clause-internal argument rather than a clause-external main predicate. This is not to deny that Focus structures in modern Yukaghir could have emerged as the result of a historical reanalysis of constructions where the Focus element functioned as a predicate, as has been suggested (in somewhat opaque terminology) in Nikolaeva \& Xelimskij (1997: 162).

Chapter 13 describes the formation of imperatives, questions, negation, quotations, exclamatives, and optatives. The main focus of Chapter 14 is coreference and discourse coherence. It discusses phenomena such as reflexivization, switch-reference, reference tracking by means of zero anaphora, agreement markers, pronominalization, and the linking of two finite clauses or two clause chains at the paragraph level.

As much as I admire this informative grammar, I have a few reservations about three aspects of the book, to which I turn in the following three sections. 


\section{Presentation of data}

The transcription in the book is intended to be "essentially phonemic" (p. 32), but there are many inconsistencies in how the language data are presented. This is quite unfortunate, since the grammar is likely to become a standard reference and its examples will certainly be cited in many works. Most often inconsistencies concern the transcription of the vowel $\phi$. For example, the vocabulary contains the word aduøn 'this one, that one' (p. 542), which in other places is written as aduon (pp. 225, 500). Similarly the word num $\phi$ 'house' (p. 550) is sometimes written as nume (pp. 66, 87, 106), køj 'boy' (p. 548) sometimes as koj (pp. 277, 536), and there are other examples. In principle these inconsistencies could reflect subphonemic variations. However, such variations are not addressed in the grammar. Moreover, in my experience with the same speakers there is no variation in the pronunciation of these words: all speakers consistently pronounce $\phi$. Therefore the transcription of $\phi$ as $e$ or $o$ is likely to represent auditory errors.

Similarly, Maslova renders the negative copula as ojl'e (pp. 145, 160, 299, $308,332,476,477,525,579)$, but according to my data it should be transcribed as $\phi j l$ ' $e$. This is confirmed by the lengthening of the final vowel. As described on pp. 55-56, the final vowel is lengthened before certain affixes. The quality of the resulting long vowel depends on the harmonic quality of the stem. In the

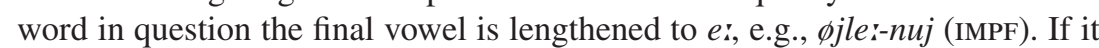
contained the back vowel $o$, the respective form would have been *ojla:-nuj, but this form does not exist.

There are numerous examples of the inconsistent use of vowel length, e.g., n'ied'i- 'speak, tell' (pp. 229, 386, 406, 419, 473, 518, 564, 580) vs. n'ied'i:(p. 550) and $a \check{z} u$ 'word' (p. 230) instead of $a \check{u} u$ ' (p. 543). The word mi:d'i: 'sledge' is sometimes written as mid'i: (e.g., p. 549), sometimes as mi:d'i (p. 438), and sometimes as mied'ir (p. 576). Such inconsistencies can be quite annoying when they occur on the same or adjacent pages and/or pertain to grammatical morphemes and functional words. Thus, the pronouns ša:r 'something' and i:le 'some' (p. 253-255) are cited as šar and ile, respectively, on pp. 71, $172,282,387,428,535$, and 580. The connective particle aji: (p. 542) is sometimes written as $a: j i$ (pp. 173, 430, 440, 456), and the postposition arqa: 'near' (pp. 268-269) is sometimes written as arqa (pp. 380, 393, 429). The question word noyo:n 'what for' is cited twice in this form on p. 488, but on the very same page it is written as noyon. The Prospective suffix is sometimes transcribed as moži- (pp. 6, 26, 175, 176) and sometimes as moži- (pp. 7, 139, 166, 167, 175, 440). The 3rd person Plural affix of transitive verbs - ya: (p. 140) is written as -ya on pp. 171, 201, 311, and 509. The iterative affixes -ji:-, $-d^{\prime}{ }^{\prime}-$ $\sim-n-d^{\prime} i-,-c ̌ i-\sim-s ' i-$, and -uji- are transcribed either with a short vowel (e.g., on pp. 131, 195, 196, 197, 221, 236, 399, 539) or with a long vowel (e.g., on pp. $193,195,197,237,287,545)$ throughout the grammar. 
The book does not explain why these words and affixes are written in several different forms. If the alternations in vowel length were free variations, this would have been worth mentioning explicitly, given how numerous they are. In fact, just as in the case of the phoneme $\phi$, I have seen no evidence that there are variations in vowel length: speakers always pronounce long vowels in the words and suffixes in question.

In other instances alternative transcriptions do reflect subphonemic variations. For instance, back vowels are optionally fronted after palatal consonants. This is reflected in transcriptional variations, e.g., jonži- 'fall asleep' (p. 547) vs. jeyžo:d'e 'dream' (p. 505). However, these variations are not addressed in the text. Other free variations are mentioned, but there is no indication that they are to be reflected in the transcriptions. It is stated on p. 30 that mid long vowels are sometimes pronounced as diphthongs, usually in stressed syllables. They are written differently throughout the book, sometimes in the same phonological environment, e.g., je:n 'other' (pp. 113, 250, 255, 281, 283, 571) vs. jien (pp. 251, 546, also jen on p. 391) and jo:bi: 'in the forest' (pp. 65, 546) vs. juobi: (pp. 259, 293, 520).

The second problem concerns segmentation into morphemes. In many cases epenthetic $u$ and $i$ are not indicated in the glosses as such. For instance, the attributive and predicative forms of numerals form the following pairs: ataq- $u-n$ and ataq-lo:- 'two', ilek-u-n and ilek-lo:- 'four', but ja:-n and ja:-lo:- 'three' (the morpheme segmentation is mine). This data demonstrates that the Attributive marker is $-n$, while the preceding $u$ is epenthetic. This is especially obvious since $-n$ is the regular Attributive marker. Nevertheless, Maslova writes the Attributive forms of numerals as ataq-un and ilek-un, respectively, suggesting in her glosses that the vowel $u$ belongs to the Attributive morpheme. The same applies to the Dative forms of personal pronouns, divided into morphemes as met-in [I-DAT], although the Dative marker is in fact $-n$. Although not mentioned in the grammar, it occurs sometimes with proper nouns, e.g., Jakutskej- $n$ 'to Jakutsk (DAT)'.

Furthermore, p. 57 states that vocalic epenthesis only occurs in word-final syllables. But it also serves to prevent ill-formed word-internal clusters. For instance, the iterative suffix is cited as -(u)̌̌u- (p. 562), but the first $u$ is epenthetic, as it appears only after consonantal stems, cf. eg- $u$ - $\check{z} u$ - 'walk (ITER)' and qodo$\check{z} u$ - 'lie (ITER)'. The idea that some word-internal occurrences of $i$ and $u$ are epenthetic explains seemingly unmotivated variations in verbal stems. For example, the verb 'come' is cited as kel- in the vocabulary, but on pp. 317, 330, and 383 the same stem is represented as kelu-. The stem 'eat' is cited as leg-, but in its derivative legite- 'feed' the morphemic division is legi-te- [eat-CAUs], while -te- is a frequent Causative affix. The same concerns the verb šoh-e:'get lost' and its Causative counterpart šohu-še-. There is no account of the alleged stem alternations kel-/kelu-, leg-/legi-, and šoh-/šohu-, although they may 
appear on the same page (e.g., p. 219). Yet, the comparison with other verbs reveals that $u$ and $i$ here are epenthetic, and consequently the morpheme division must be kel-u-, leg-i-, and šoh-u-. As a matter of fact, most occurrences of short $i$ and $u$ in non-first syllables are epenthetic. Although the phonological environment of word-internal epenthesis is not always clear, most cases are straightforward. However, the grammar does not contain any discussion of this matter. Epenthetic vowels are glossed as parts of either stems or affixes and, as a result, some morphemes occur in several shapes.

There are other inconsistencies in representing verbal stems. For instance, the frequent stem 'go' is cited in at least five variants: kew- (pp. 106, 107, 408, 428, 462, 467, 506, 521), kebe- (pp. 165, 170, 429), keb- (pp. 459, 486, 569), køu- (p. 320), and kewe- (pp. 164, 181, 259, 375, 395, 442, 520, 558, 566, $567,568)$. This word is given in the vocabulary in the latter variant, although the same entry contains its derivatives $k \phi w$-de- 'drive out' and kep-či- (the Iterative Causative). But the vowel $e$ in the second syllable is likely to belong to the perfective suffix, which often follows the stem. This suffix is cited as $-j-$ on p. 559, but for a number of verbs it takes the shape $-e j-\sim-a j-$, cf. moro-l-aj[dress- $\emptyset$-PFV] on p. 559 and jed-ej- [be.visible-PFv] on p. 392. ${ }^{4}$

There is no definition of the plus sign (+), which is sometimes employed to separate morphemes. I assume the idea is thereby to indicate a somewhat looser connection between the respective morpheme and the rest of the word. However, the morphological status of such morphemes is not addressed. The plus is used for what Maslova refers to as prefixes (more precisely they can be termed proclitics, see Endo (1997)). They show properties of both bound morphemes and free words. On the one hand, they are separable from the host word and do not participate in stress assignment. Vowel-final proclitics can precede a vowel-initial stem, thus creating a sequence of two vowels, which is normally prohibited word-internally. On the other hand, the vowel optionally assimilates in rounding to the root. Next, the plus is employed before the Prospective marker -možu:- and the copula go:-. These morphemes are bound to the stem, but do not participate in vowel harmony or, rather, they create their own harmonic domain and bear independent stress. Finally, the plus sign is used to separate the Attributive nominal from the head. The Attributive is fully productive and can be derived from virtually any noun. It is phonologically independent from the following word except that the Attributive marker typically shows the alternation $n \sim d$ depending on the quality of the next segment. In sum, there are at least three different cases here, but there is no discussion of this matter.

4. The vowel-initial variant of the affix may contract with the stem-final vowel, cf. čolho- 'hollow'vs. čolh-aj- (PFV). On p. 191 this word is written as čolha-j-, but this transcription leaves the stem-final alternation $o \sim a$ unexplained. 
Lastly, although in the majority of cases Maslova has provided satisfactory and well-formulated translations, some corrections can be made. For example, amun'd'a: (p. 138) is not any kind of bony fish, as its literal translation may suggest, but a specific sort of fish, namely, Amur ide (Leuciscus waleckii). ${ }^{5}$ The stem tami- (p. 152) does not mean 'help' but 'put on (clothes)' (cf. tamiin Jochelson 1900), while emes' $k e$ (p. 385) is not 'noiselessly' but 'suddenly' (cf. Yakut emiske 'suddenly'). The word šøtkuri: (pp. 290, 490) is translated as 'ski', but it means 'boots with soles made of the fur from the inside of reindeer hooves’ (cf. šotkuri in Jochelson 1900).

\section{Comprehensiveness}

My second reservation is related to the coverage of the Yukaghir material. Obviously, no grammatical account can be fully comprehensive and Maslova is well aware of this fact. However she states that the purpose of the grammar is "to cover all attested forms and constructions of contemporary Kolyma Yukaghir" (p. 13). Although the book provides a very rich account of the language, I would not say that this promise is entirely fulfilled. In this section I will cite a number of grammatical facts which are not discussed in the book but appear to belong to the core grammar. Some of them can be found in published works on Yukaghir including the source analyzed by Maslova. A few others are attested in the course of my own fieldwork. For the most part I will not provide references and examples for reasons of space, but they are available upon request.

The description of nominal derivational patterns is not quite comprehensive. Firstly, some additions could have been made to the list of nominal derivational suffixes. The list of non-productive suffixes on $\mathrm{p} .134$ can be augmented by -me, $-l e \sim-l ' e,-r$, and several others (see Krejnovič 1982). The nominalizer -ben is not only used to substantivize deverbal nouns, but can also substantivize adverbs and the Temporal form of nouns, e.g., pude-ben 'top' from pude 'over, upward'. Action Nominals derived from qualitative verbs can be nominalized by means of the pronominal element-tay. What Maslova describes as the suffix $-(i) l$ ' (p. 134) is -l', while $i$ is epenthetic (see Section 2). This suffix seems to represent a variant of the frequent nominal suffix $-l$. The latter is attested, for example, in such words as $a d-i-l$ 'youth' (cf. $a d-u \phi$ 'son, lit. youth child') and $l u d-u$-l 'iron' (cf. lun-bug $\phi$ 'caldron, lit. iron box'). The grammar does not list

5. Incidentally, this word is said to be formed via the lexicalization of the Active attributive form, presumably of the Proprietive verb amun-n'e- 'have bones'. However, the attributive form of this verb is amun-n'e-je rather than amun'd'a: since, first, it never ends in $a$ : (contrary to Maslova's assertion on p. 137) and, second, the Proprietive suffix here is - $n$ ' $e$ - rather than $-n$ '-. The word amun'd'a: is likely to be formed from amun 'bone' with the suffix -ča: 'abundant in something' through the following regular phonological development: amun $+\check{c} a$ : > amund'a: $>$ amun'd'a: 
the suffix $-l$ among nominal derivational suffixes, although it was mentioned by Krejnovič (1982: 85-86). Instead Maslova states on p. 136 that many nouns in $-l$ result from the lexicalization of deverbal Action Nominals. However, for a number of nouns in $-l$, such as those cited above, no corresponding verb exists in modern Yukaghir. Although they are not synchronically derived, the affix $-l$ can still be identified based on other related forms.

Second, p. 134 says that the only regular type of nominal compounding is the pattern where the first component of the compound takes the Attributive marker $-d \sim-n$. No examples of another, perhaps less regular, type where both components occur in the basic form are cited. In fact, there are many, e.g., o:žii-nodo 'duck, lit. water bird' and melut-pod'erqo 'round metal decoration women wore on the chest, lit. chest sun'. In some compounds the first component is reduced, as in the words cited in the previous paragraph, or relates to a qualitative verbal stem, e.g., kej-lebejdi: 'cowberry, lit. red berry' and čam-ani: 'sheefish (Stenodus leucichthys), lit. large fish'.

Derivational patterns of smaller grammatical classes could have been described in more detail. The section on interjections on pp. 489-490 does not mention that interjections have some morphology. A subclass of interjections is derived from verbs by means of the suffix - $g e \sim-h e$. Two examples are cited in the grammar, but there are many more, e.g., mejlu-ge 'what a sorrow!' and pažilu-he 'it is disgusting!'. A few items are missing from the list of postpositions, which is intended to comprise "all attested forms" (p. 267), e.g., mi:de 'along, according to', s'is'kin 'along' (see p. 566 of the grammar), me:kl'e: (with derivatives) 'near', titel'o: 'like, as' (see p. 569 of the grammar), and n'a:čin 'against, in front of'. Information about particles, conjunctions, and focus items is scattered throughout the book, but it would be useful to see a more or less representative list of them in one place. Some are not discussed, e.g., jaqaj 'too, also', 6 ere 'only', as well as a number of discourse particles.

The grammar does not mention words derived by means of the suffix $-k e \sim$ -qo, such as $p \phi m-k e$ 'round' (cf. pøm-ne- 'round'), čič-ke 'long, tall' (cf. čitne- 'long'), pon'-qo 'white' (cf. pojne- 'white'), and jolo-qo 'last' (cf. jolo:'last'). This group is remarkable because it shows neither nominal nor verbal properties. The words in question have no inflectional morphology and, unlike nouns and verbs, are only used in attributive function. In fact, they can be termed adjectives. As mentioned above, Maslova concludes that Yukaghir has no adjectives, but this is not entirely accurate. She herself points out that there are two pairs of attributive words that cannot be classified as nouns or verbs, namely juku 'small' vs. čomo 'big', and čø:l'e 'old, ancient' vs. il'l'e 'new, fresh, (an)other'. The first pair is mostly used in frozen collocations but

6. Maslova transcribes it as ieqaij. 
the second freely combines with any noun, and so do the attributive words in $-k e \sim-q o$. To this list I can add the rare word n'an'če 'big, large'. So Yukaghir appears to have a small closed class of basic adjectives which includes at least five non-derived attributive words and several derived words showing totally idiosyncratic grammatical behavior. This conclusion seems to argue against Wetzer's (1996) point that even in languages where adjectives are a distinct class they tend to associate with one of the two major word classes, noun or verb.

Some additions could have been made to the inflectional patterns. It is not mentioned that the Transformative form of nouns is compatible with the oblique Possessive affix - $d e$ - and so perhaps can be analyzed as a case. On p. 234 it is stated that Free Possessive forms are typical of personal pronouns, but absent from the nominal paradigm. However nouns are able to attach the same Free Possessive marker -l'e, and so does the interrogative pronoun kin 'who'. Although the Free Possessive forms primarily form headless NPs, sometimes they serve as attributes, e.g., pug $\phi$-l'e čug $\phi$ [summer-Poss road] 'summer road'. When describing the morphology of indefinite pronouns in Chapter 7, the author surprisingly omits the primary type, namely indefinite pronouns formed from interrogative pronouns by means of the clitic ere $\sim$ ure. This pattern is quite regular and can derive indefinite pronouns from virtually any interrogative. The clitic follows the case inflection, cf. kin-ere 'somebody [who-INDF]' and kin-nin-ere 'to somebody [who-DAT-INDF]'. As in many languages, it also functions as a Focus item meaning 'only'. There are other lacunae in the description of the pronominal system.

As for verbal morphology, Kolyma Yukaghir has an additional modal form not mentioned in the grammar. This form is derived with the suffix -mi:bi:-bi:bi:- and typically denotes a situation which the speaker judges as being certain to take place, e.g., nu:-mi:bi:- $m$ [find-MODAL-TR.3sG] '(s)he will definitely find it', but can also express various deontic meanings. As stated on p. 158, the Different-Subject converb takes the Possessive marker - de- if the subject is $3 \mathrm{rd}$ person. However, there is no Possessive marking in constructions with the expletive subject $p \phi n$, e.g., $p \phi n$ emidej-ge 'when it got dark [darken-Ds]'. Sometimes the Possessive marker is absent even with a referential subject. It is not mentioned that the Periphrastic Past is compatible with the Periphrastic Prospective. The resulting form expresses intention in the past and has three components: the Supine of the content verb, the attributive form of the verb $l$ 'e- 'be' (optionally with the nominalizer -ben), and (with 1st or 2 nd person subject) the copula $o{ }^{\prime}$ - that takes subject agreement: ejre-din l'e-j(-ben) $o$ '- $d$ 'e [walk-SUP be-ATTR(-RELNR) COP-INTR.1sG] 'I was going to walk'.

The functions of the verbal categories could have been described in more detail. The pro-verb monohot- is not exclusively used for requests to repeat the previous utterance (p. 480), but as noticed by Krejnovič, has a whole paradigm 
and serves in other functions, namely, in embedded questions and with the negative marker for negation: el-monohod-i [NEG-say.what-INTR.3sG] '(s)he did not say anything'. The grammar says that the Interrogative forms are only used with questions words (p. 143). But the 1st person Singular Interrogative can have a hortative meaning (cf. Krejnovič 1982: 149-151). A question word is not required in this case.

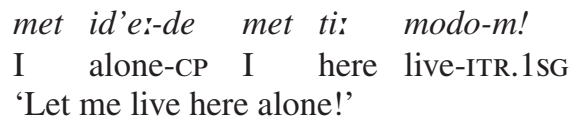

This form of the Interrogative often combines with the hortative particle $o$ što: 'let'.

Turning now to syntax, a few case functions and valence patterns are not accounted for. The Dative often expresses the purpose of a movement in combination with the frozen Imperfective converb of the copula 'be' l'et. In addition to the metaphorical meanings of the Ablative listed on pp. 111-113, the Ablative denotes material and a partitive object, mainly with imperative verbs, see example (910b) in the grammar and Nikolaeva \& Xelimskij (1997: 160). The Instrumental denotes the measure of comparison. The Transformative functions as an argument of significantly more verbs than the two listed on p. 449, e.g., qarte- 'divide into parts' and o:ži i- 'consider as'. As described on pp. 352-353 and 356-357, two-place intransitive verbs of speech take the Dative, while intransitive verbs of movement open a directional slot, i.e., their second argument can be expressed by Dative, Locative, or a postpositional phrase. But there are other patterns involving these cases. Some verbs of emotions and perception take the Dative or a postpositional phrase, while the Locative is impossible. Thus, the verb jø:de- 'look at' takes the object expressed by the Dative or a postpositional phrase with the postposition layi(de) 'at'. On the contrary, there are verbs that only take the Locative, e.g., čande- 'rub oneself against' or tan'n'e- 'owe'.

On p. 213 it is stated that the causee of transitive causatives is encoded as the indirect object, i.e., is in the Dative. It is not mentioned that the transitive causee exhibits alternative grammatical encodings: in addition to Dative, it may be encoded as the direct object and take the Accusative or Predicative. This fact was discussed in Maslova's own earlier paper on Yukaghir causatives (Maslova 1993). The causative construction with the direct object causee is formally identical to other double object patterns: ditransitive double object constructions (pp. 354-355) and the constructions where some kind of part-whole relationship obtains between two objects (pp. 93-94). Note that geographically close Tungusic languages show the same three types of double object construction, while the distinction between the direct object and the indirect 
object causee correlates with an interpretational difference: the former is available when the construction has a factitive meaning, while the latter allows both factitive and permissive interpretations. It would be interesting to see whether there is a similar distinction in Yukaghir.

Secondary predicates are not addressed in the grammar. Yet Yukaghir possesses quite a distinct strategy for resultative secondary predicates. The verbal form coincides with the verbal stem augmented by the Resultative marker $-O$ :.

a. ф:rpe-p-ki amd-o: qodo:-l'el-ni

children-PL-3 die-RES lie-INFR-INTR.3PL

'(It turns out that) his children lie dead.'

b. Noj aysi-t lebe: arimel-ge an-i-pe-n'e

Noah search-SS.IMPF earth bottom-LOC fish- Ø-PL-COM

n'aha: ejr-o: nuy-na:

together walk-RES find-TR.3PL

'They looked for Noah and found him walking at the bottom of the earth together with the fishes.'

As can be seen from these examples, the resultative secondary predicate is controlled by either the subject (4a) or the direct object (4b).

The grammar does not describe many patterns of complex sentence formation, such as temporal clauses with the Temporal form of Action Nominals, causal clauses formed with the Action Nominal in the Instrumental, purpose clauses headed by the Transformative form of the Action Nominal, "instead"-clauses formed by means of the Action Nominal with the postposition ta:her 'instead', relative clauses formed with Different-Subject Converbs, and comparative finite clauses with the conjunction n'eno:de 'as if'. Only three types of sentential objects are listed: the object complement clause, the Instrumental complement clause, and the directional (Locative or Dative) complement clause. However, some sentential objects are expressed with the Action Nominal in the Prolative: they involve such verbs as $\check{\phi} \phi$ rile- 'write about' and pundu- 'tell about', as well as the expression pas'irbe 'thanks for'. The lists of complement-taking verbs could have been expanded. For instance, the verb l'orqaj- 'be unable' introduces the Instrumental complement, and there are significantly more predicates that take the sentential subject, such as čejluke:j 'late, long ago' and the like.

Finite complementation is not addressed. Many descriptions of Siberian languages suggest that the native subordination strategies involve non-finite forms and no complementizers, while alternative strategies, if present, have developed under Russian influence. Yet a number of languages exhibit native types of finite complementation. A frequent historical source of such complementizers is verbs that have undergone some kind of semantic bleaching (cf. Vincent 1993: 159). Languages areally close to Yukaghir use grammaticalized forms of 


\section{Irina Nikolaeva}

the verb of saying. For example, in the Tungusic languages Evenki (Brodskaja 1988: 72-73) and Udihe (Nikolaeva \& Tolskaya 2001: 662-664) the converb of the verb of saying serves as a complementizer in the complement clauses which do not necessarily express the content of speech, as well as in purpose clauses. A similar construction exists in Yakut (Čeremisina 1995: 225-226) and Buriat (Koptjevskaja-Tamm 1993: 29). Yukaghir shares this property. It frequently uses the complementizer monut grammaticalized from the SameSubject Imperfective converb of the verb mon- 'say' which has fully lost its original semantics. It may introduce complement clauses with verbs other than verbs of saying (5a) or purpose clauses (see (7) below). The finite complement clause has the verb in the Indicative or the Interrogative.

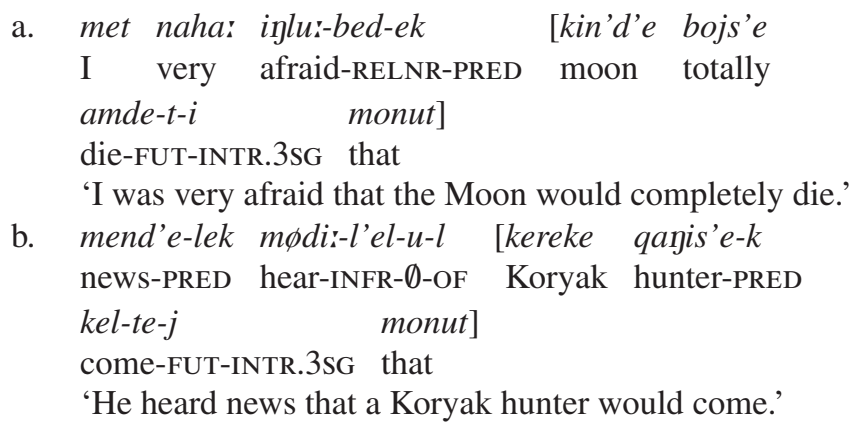

Example (5b) additionally demonstrates that monut cannot be analyzed as a converb because there is no same-subject relationship between the main clause subject and the presumed subject of monut.

Interestingly, the grammaticalization process in Yukaghir goes even further. The element monut can serve as a kind of evidential marker in the main clause.

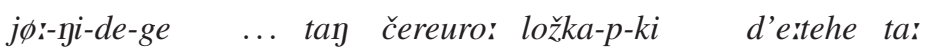

$$
\begin{aligned}
& \text { see-PL-POSS-DS that silver spoon-PL-POSS still there } \\
& \text { pon'o:-l'el du, čugф-ge lфudus-l'el du } \\
& \text { remain-INFR.INTR.3SG either road-LOC fall-INFR.INTR.3SG either } \\
& \text { monut } \\
& \text { INFR } \\
& \text { 'They saw that either his silver spoons had remained there or they had } \\
& \text { fallen out on the road.' }
\end{aligned}
$$

In (6) the element monut is located in the main clause and does not function as a complementizer. Its role is apparently to strengthen the meaning of the Inferential marker: it indicates that the respective event has not been witnessed directly but was inferred on the basis of secondary evidence. What we find here is a subordinate clause which functions as a main clause. This sentence is an 
example of insubordination defined by Evans (forthcoming) as "conventionalized independent (main-clause) use of what, on prima facie evidence, appears to be a formally subordinate clause". Evans argues that epistemic and evidential meanings are commonly associated with the insubordinated structure, and this is exactly what is observed in Kolyma Yukaghir.

I would like to have seen more information concentrated in one place in the grammar on disjunction, subjectless (impersonal) constructions, and the order of attributive modifiers within the NP (relative clauses, nominal and verbal attributive forms). There is no summarizing discussion of the clausal position of adverbials and Focus elements. The grammar says that the Focus normally precedes the verb (p. 341), but it remains unclear whether Focus is associated with the immediately preverbal structural position as in many SOV languages (Kim 1988, É. Kiss (ed.) 1995). A few examples from the grammar suggest that lexical material may intervene between the Focus constituent and the verb, but exactly what may be located there and under which conditions is not discussed. Related to this, on pp. 480-481 Maslova says that wh-question words are either sentence-initial or occur in the position most typical of the respective constituent type. However, only very short examples with no more than two or three constituents are provided to illustrate this point, so it is not obvious from the surface order whether the non-initial wh-question is separable from the verb.

\section{Interpretations}

To begin with, I would like to stress that most of Maslova's interpretations of the material are convincing and well-argued. However, there are a few cases where I believe a different analysis can be provided.

In the phonology chapter consonantal alternations could have been addressed in more detail. On pp. 39-42 Maslova describes syllable-final alternations of voiced consonants such as devoicing, assimilation to a nasal, word-final nasalization, and $d \sim n$ alternation in nominalizers and Attributive nominal forms. These processes are treated as independent and it is not clear if they interact and whether they involve the same stems. In fact, some words show syllable-final devoicing whereas others show nasalization in the same position, cf. pad-um 'cook (TR.3SG)' but pat (IMP) vs. jad-um 'send (TR.3SG)' but jan (IMP).

In fact, the range of alternations of syllable-final voiced consonants is broader than suggested in the grammar, and they crucially fall into two types. One type involves the consonants $d, d^{\prime}, g$, and $h$. They alternate with the (near-) homorganic nasals before a consonant or a pause. This alternation does not depend on the quality of the next segment, cf. jad-um 'send (TR.3sG)') but jan (IMP), jan-te-m (FUT-TR.3SG), jan-delle (SS.PFV), jan-mele (OF.3sG), jan-ya: (TR.3PL), etc. The alternation $d \sim n$ is especially frequent and is by no means 


\section{Irina Nikolaeva}

limited to nominalizers, Attributive forms, and some verbs, as suggested in the grammar. The second type of alternations involves the consonants $d, g, h$, and $b$. They have different realizations in syllable-final position depending on the quality of the next segment. Many of them were described in Krejnovič (1982). For example, $d$ is realized as $t$ before an occlusive or a pause, as $l$ before $l$, and as $n$ before a nasal, while $g$ is realized as $k$ before a voiceless occlusive or a pause, as $\eta$ before a voiced occlusive or $\eta$, as $m$ before $m$ and as $u \sim w$ before $l$. These alternations reflect the individual assimilative properties of each consonant and do not conform to the general rule "occlusive + vowel $\sim$ homorganic nasal + consonant", as in the first type. ${ }^{7}$

Thus, the consonants $d, g$, and $h$ show two types of alternations. This situation can be lexically marked, for example, by introducing different diacritic signs for different types of voiced consonants or representing the first type as an underlying cluster. In any case it is worth mentioning in a comprehensive grammar that there are two classes of stems with different assimilative properties.

Some objections can be made to the analysis of the consonantal inventory. According to Maslova, $b$ is absent as a separate phoneme in Kolyma Yukaghir. She takes $b$ to be a variant of $w$. However, $b$ shows the range of assimilative alternations parallel to the alternations of other voiced consonants in syllablefinal position: $p$ before a pause, $u \sim w$ before an occlusive, $m$ or $l$, and $\eta$ before $\eta$. So we are likely to be dealing here with the voiced labial stop phoneme. In this instance the system of occlusives is symmetrical. All voiceless occlusives have a voiced counterpart: $p \sim b, t \sim d, k \sim g, \check{c} \sim d, \check{s} \sim \check{z}$, and $q \sim h$ (in the latter there is also a difference in the manner of articulation).

On the other hand, $w$ does not seem to have phonemic status, but is rather an optional pronunciation of either $b$ or $u$. When $u$ is syllable-final, it is part of a diphthong, e.g., what Maslova transcribes as $k \phi w d e$ - 'drive out' is phonologically kфude-. In a similar manner, some occurrences of $j$ are better analyzed as glide components of raising diphthongs than as consonants. This analysis is supported by the phonotactic regularities of the language. On p. 34 Maslova says that consonantal clusters are disallowed in syllable-final position, except for $j$-initial clusters, e.g., qojl 'God' and qojl-get (ABL). The diphthong analysis strengthens the generalization: if $j$ and $w$ are analyzed as vocalic, such words do not present exceptions. Moreover, the diphthongs behave as long vowels with respect to consonantal epenthesis, stress assignment. and other phonological processes conditioned by syllable weight.

7. This results from their historical origin: voiced consonants that participate in alternations of the first type go back to clusters, while voiced consonants that participate in alternations of the second type go back to single consonants (see Nikolaeva 1998). 
Next, the account of vocalism and vowel harmony appears to miss some generalizations. On pp. 52-55 Maslova correctly says that all stems fall into two morphonological classes, $+E$-stems and $-E$-stems. The "morphophoneme" $E$ is postulated on the basis of its idiosyncratic morphonological behavior. In particular, a number of suffixes show the alternation $\mathrm{CE} \sim \mathrm{C}$. When they follow each other, the allophones are chosen in an alternating manner so that they create sequences $\mathrm{CE}-\mathrm{C}-\mathrm{CE}$ or $\mathrm{C}-\mathrm{CE}-\mathrm{C}{ }^{8}{ }^{8}$ What is not mentioned is that the distribution of $E$ is not random. Bisyllabic stems ending in a short vowel can only be of the types CV:CE, CVCCE, and CVCV, where $\mathrm{V}$ is not equal to $E$. The stems *CV:CV, $* \mathrm{CVCCV}$, or $* \mathrm{CVCE}$ are ruled out. In subsequent syllables all short non-high vowels are represented as $E$, as evidenced by their alternations and assimilative properties. This leads to the following generalization: the only non-high short vowel that occurs after the initial sequence CVC, CVCV, or CV: in native words is $E$. In other words, short non-high vowels are underspecified with respect to place of articulation after the first bimoraic foot (for details see Nikolaeva 1998). ${ }^{9}$

This bears on the treatment of vowel harmony. Maslova's basic insights can be formulated in the following way: (i) vowel harmony is based on the frontness feature, while the only vowel that can optionally undergo labial harmony is $E$; (ii) the domain of harmony is the word; (iii) harmony applies to long and short vowels; and (iv) apart from optional rounding, $E$ does not participate in vowel harmony but is realized as $e$. However, statement (iv) is only partially true. $E$ shows optional assimilation to $o, e$, and sometimes $a$, but is mostly represented as the neutral vowel schwa (rather than $e$ ). Generalizations (i) are (ii) do not seem to hold. Since the only non-high vowel that occurs after the first foot is the non-harmonizing $E$, harmony is restricted to the first foot, i.e., the structures \#CVCV. In contrast to what Maslova says, they show rounding harmony in addition to frontness harmony, but rounding harmony operates only on a subsystem of vowels, namely on non-front vowels. These must share the rounding feature within the first foot, therefore the structures ${ }^{*} \mathrm{CaC} o$ or $* \mathrm{CoC} a$ are forbidden.

As for long vowels, they participate in harmony only when they correspond to $E$ which has undergone secondary lengthening. In this case we find frontback harmonic pairs, for example, the Ingressive suffix $-a:^{-} \sim-e^{-}$. However, the grammar does not make it explicit that there are a number of non-harmon-

8. On p. 49 Maslova refers to Krejnovič (1982) for this generalization. In fact, Krejnovič only discussed the suffixes which immediately follow the root and concluded that their phonological shape was determined by the root-final vowel. He made no explicit claims about the shape of the following suffix in the sequence.

9. This most recent paper on Yukaghir phonology is not in Maslova's list of references. The paper demonstrates among other things that the alternations of $E$ are prosodically motivated. 
izing suffixes with long vowels (e.g., Diminutive -de: and Causative-Resultative $-e$ :- $^{-}$, which apparently do not result from the lengthening of $E$. Long round vowels do not harmonize either. So with the exception of secondary long vowels and the optional assimilation of $E$ the domain of harmony is the first foot. However, synharmonism, i.e., alternations of velar and uvular consonants depending of the frontness of the stem, applies to the whole word, except for a number of inflectional morphemes. Although on p. 37 Maslova promises to give a list of such morphemes, it is not provided in the grammar.

Turning now to verbal morphology, on p. 140 the following paradigm for the Imperative is described: $2 \mathrm{sG}-k$ (Simple form), -gek (Complex form), 3sG -gen, 1PL -ge, 2PL - nik (Simple form), -nigek (Complex form), and 3PL - nigen. This analysis seems to be influenced by the Russian tradition most richly represented in the typological work of Xrakovskij (2001). The authors of this volume argue that the core meaning of the imperative is speech causation irrespective of who is the performer of the prescribed action. Under this broad definition the imperative subject's person is irrelevant.

However, there are good formal and semantic grounds to draw a distinction between imperatives and what can be referred to as hortatives. Imperatives are prototypically used to express directive force. Roughly speaking, this means that the speaker intends the addressee to take the utterance as a reason to perform action X and believes that the addressee can do X (Allan 1994). The cooperative response from the addressee would be the doing of $\mathrm{X}$. This description reflects the interaction between speech act participants and has grammatical consequences for the imperative clause type: the imperative is in 2nd person (Palmer 1986; Bybee, Perkins, \& Pagliuca 1994; Potsdam 1998; and others). On the other hand, hortatives are not associated with directive force but are closer to expressives and are often loaded with additional modal meanings. If, in Sadock's (1994) terminology, imperatives emphasize the effective, social aspect of speech, hortatives rather express an affective, emotional aspect primarily used to display the speaker's feelings. The respective speech act can roughly be defined as follows: the speaker believes it appropriate to express a wish that situation $\mathrm{X}$ takes place and intends the utterance to be taken as expressing his/her wish that it takes place. Unlike imperatives, hortatives do not necessarily presuppose a non-verbal response. Therefore they do not require the speaker's assumption that the addressee can carry out action $\mathrm{X}$ and do not even require the presence of the addressee for a successful speech act. Since hortatives are not primarily directive, there are no restrictions on the hortative subject: they can express exhortations to any person (Sadock \& Zwicky 1985).

Hortatives tend to formally differ from 2 nd person imperatives. For example, in a number of African languages there are special forms usually referred to as subjunctive, injunctive, hortative, or optative (see Carlson 1994 for Supyire, Dimmendaal 1983 for Turkana, and Bergelson 2001 for Bambara). They serve 
as complements of modality or manipulative verbs and may form a dependent purpose clause. But when used independently, these forms either fulfill a sequential narrative function or serve as hortatives. Unlike imperatives, which are limited to 2 nd person and express direct prescriptions, hortatives occur in all three persons and convey the illocutionary meaning of inducement or wish. When they are in the 2nd person, they express an indirect causation and function as more polite or remote future imperatives. Thus, although imperatives and hortatives have common components in their meaning (the reference to the future event intended by the speaker), languages often grammaticalize the clause type distinction between them.

The situation in Yukaghir is basically similar. Maslova's paradigm appears to conflate two different moods, the Imperative and the Hortative. The Imperative is only employed in the directive function and is limited to the 2 nd person. It is marked with the suffixes $-k$ in the Singular and $-n i k$ in the Plural. The Hortative has the following affixes: 2SG -gek, 3SG -gen, 1PL -ge, 2PL -nigek, and 3PL-yigen. There is no distinct form for 1st person Singular Hortative, probably because the respective meaning is expressed by 1st person Singular Interrogative (see (3) above). This analysis makes both paradigms morphologically homogeneous.

The Hortative is not intended as a directive but rather emphasizes the speaker's emotional state. When used in the 2 nd person it is perceived as a remote imperative. Indeed, according to Maslova, the difference between the Simple and the Complex forms of the 2 nd person Imperative (i.e., between Imperative and 2nd person Hortative, in my terminology) is that the latter expresses commands or requests that have to be fulfilled later. Most importantly, although this is not mentioned in the grammar, the Hortative can be used in dependent clauses, normally in purpose clauses with the complementizer monut 'for, in order to, so that'.

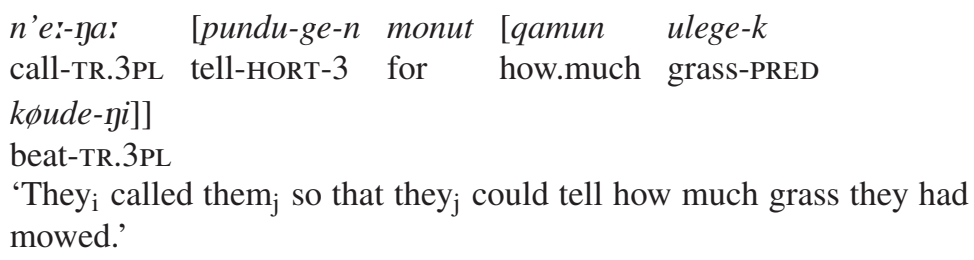

As noticed in Sadock \& Zwicky (1985: 174), true imperatives do not occur in dependent clauses, but examples such as (7) are predicted by the Hortative analysis.

Next, Kolyma Yukaghir has two possessive constructions with lexical possessors: with and without a 3rd person cross-reference marker on the head. Under Maslova's analysis, in both cases the possessor is NP-internal. The agreeing 
possessor is not analyzed as a syntactic topic, because it does not have to be clause-initial and may not be separated from the possessum by other clausal constituents. What is more, there is no evidence for the prominence of syntactic topics other than possessors in Yukaghir syntax.

However, a topic analysis cannot be altogether excluded. First, the generalization that the agreeing possessor must be NP-internal appears to be too strong. In some instances it can be separated from the rest of the NP, as in (8) where it is separated by a free-standing adverb ta:t 'so, then'.

$$
\begin{aligned}
& \text { pulun-de: ta:t šaši-gi фjl'e } \\
& \text { old.man-DIM so trap-POSS NEG.3sG } \\
& \text { 'So the old man had no trap.' }
\end{aligned}
$$

Maslova also cites one example (p. 345) where the agreeing possessor is rightdetached, i.e., postposed after the clause as some kind of afterthought. This shows that the agreeing possessor can be adjoined to the clause either from the right or from the left. In the latter case it is reminiscent of double-subject constructions in languages such as Japanese and Chinese. Second, other languages (Ob-Ugric and Samoyedic) employ a similar detached construction to topicalize the possessor in the absence of non-possessor clause-external topics. In these languages the topical status of arguments is systematically expressed by clause-internal means. It is conceivable that the Yukaghir system of Focus marking provides sufficient formal distinction between topical and non-topical participants. Since the possessor is not involved in this system, topicalization of the possessor is encoded via syntactic dislocation.

On the other hand, as correctly argued in the grammar (pp. 303-304), when the agreeing possessor is NP-internal, it is structurally somewhat more autonomous from the head than the non-agreeing possessor. The demonstrative preceding the agreeing possessor modifies the latter (9a), while in the absence of possessive agreement two interpretations are possible (9b).

$$
\begin{aligned}
& \text { a. tiy pulut terike-gi } \\
& \text { this old.man wife-Poss } \\
& \text { 'the wife of this old man; *this wife of the old man's' } \\
& \text { b. tiy pulut terike } \\
& \text { this old.man wife } \\
& \text { 'the wife of this old man; this wife of the old man's' }
\end{aligned}
$$

Maslova generalizes on the basis of similar data that an NP where the possessor triggers agreement cannot form a constituent of a larger NP. Apparently, what she means by a "larger NP" is an NP where the head noun takes another dependent in addition to the possessor. Yet, the head-marked possessum can take any dependents, including demonstratives. What is important is their position: they 
must follow the possessor. If the demonstrative referring to the possessum is located between the possessor and the latter, possessive agreement is required, e.g.:

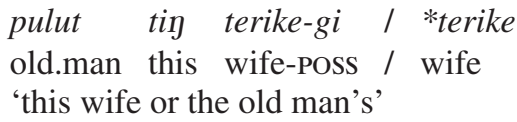

The contrast between (9b) and (10) appears to indicate that the phrase-internal positions of the agreeing and non-agreeing possessor differ: the former precedes the determiner and the latter follows it. To put it differently, the agreeing possessor is located at the left periphery of the NP.

Thus, the constructions with the agreeing possessor seem to fall into two types. In the first type the possessor and the possessum do not form a single $\mathrm{NP}$, but the possessor corresponds to an external topic. In the second type the possessor remains NP-internal, but its position in the NP is such that it precedes all other NP-internal constituents. This situation is not typologically unique. As well as the Ob-Ugric and Samoyedic mentioned above, it exists in another Uralic language, Hungarian (Szabolcsi 1994).

From a functional perspective, Maslova argues that the agreeing possessor is construed either as the clausal topic or as a participant involved in the clausal situation. This creates a sort of form-function mismatch. Although under her analysis the possessor remains NP-internal, it plays an independent role in the overall information structure of the clause (pp. 296-303). However, sometimes neither topic nor "involvement" interpretations seem to be appropriate for the NP-internal possessor, e.g.:

$$
\begin{aligned}
& \text { tabun kin zajezdka-gi? } \\
& \text { that who fish.trap-POss } \\
& \text { 'Whose fish trap is that?' }
\end{aligned}
$$

In (11) the possessor kin cannot be topical, as it corresponds to a wh-question and so is associated with the Focus function. It is equally unlikely that its referent (if any) is conceived as a participant of the situation. So the NP-internal agreeing possessor does not always have clause-level prominence. It may be worth considering that it could be prominent at the level of the NP, as supported by the fact that in most cases it tends to be inalienable and therefore indispensable for the conceptualization of the possessum. If this is on the right track, the structure is essentially iconic. Both the external and the internal agreeing possessors are assigned a special level of prominence in the interpretation of their respective syntactic domain, i.e., the clause and the NP.

Related to that is the analysis of relative clauses. They are construed as possessive constructions: the relative clause subject is encoded as grammatical 
possessor, i.e., it takes the same form as the possessor in regular possessive constructions. According to the grammar, relative clauses fall into two classes. In the Nominal strategy the subject is construed as the possessor of the dependent verbal form. In the Attributive strategy the subject can be formally construed as the possessor of the relativized NP.

These constructions are formally distinguished by the placement of the possessive marker cross-referencing the subject of the relative clause: in the Attributive relative construction, it is placed on the head noun, in the Nominal relative construction, on the verb form itself. (pp. 416-417)

This classification may be worth rethinking, unless the two types are shown to exhibit further syntactic distinctions. First, the grammar does not provide an account of what determines possessive agreement in relative clauses and whether the conditions applying to it are similar to those applying to regular possessive constructions. In the Attributive strategy the possessive marker is optional, cf. examples (743a) and (743d) from the grammar, repeated here in a modified version.
a. odu-pe modo-l jalhil-pe-gi
[Yukaghir-PL live-ANR] lake-PL-POSS
'the lake where the Yukaghirs lived'
b. tin lebe:-ge odu-pe titt-id'e: modo-l para:-ge [this earth-LOC Yukaghir-PL they-INTS live-ANR] time-LOC 'at the time when only the Yukaghirs inhabited this land'

In (12a) possessive agreement on the head cross-references the relative clause subject, but in (12b) the agreement morpheme is absent. Still (12b) represents the Attributive strategy. In contrast, the Nominal strategy is said not to allow optionality: the possessive marking must be present on the verbal form. Consider (13), which repeats example (748b) from the book.

$$
\begin{aligned}
& \text { č } \phi: l ' e-d \quad \text { omni:-pe en-pe-de para:-ge } \\
& \text { [ancient-ATTR people-PL live-PL-POss] time-LOC } \\
& \text { 'at the time when ancient families were alive' }
\end{aligned}
$$

As was mentioned above, possessive agreement is not obligatory and is conditioned by the functional prominence of the lexical possessor. If the suggested parallelism between possessive constructions and relative clauses is to be maintained, we can expect that relative clauses demonstrate similar effects independently of the location of the suffix. That is, the possessive suffix is likely to be optional both in Nominal and Attributive relatives.

Second, in the absence of overt possessive marking it is virtually impossible to decide which of the two strategies we are dealing with. This concerns the relative clauses where the subject is 1st or 2nd person and possessive agreement is 
altogether impossible, as well as the clauses with the non-agreeing 3rd person subject. For instance, (12b) can be classified with (13) rather than with (12a). Moreover, one example in the grammar (747a) demonstrates that the possessive affix expressing subject agreement can be located on both the head noun and the Action Nominal. This example does not fit neatly into the classification of relative clauses into Attributive and Nominal.

On p. 369 clause chaining is defined as "a structure in which one (typically final) clause contains a finite verb form, and each non-final clause is marked to indicate whether or not it has the same subject as the controlling clause". Clause chaining is employed both to conjoin clauses and to modify the proposition rendered by the finite clause. What is more, Maslova in principle does not want to draw a strict distinction between coordination and subordination in Yukaghir. She states that there are two structural types of chains: the linear structure, where a switch-reference clause is followed by the controlling clause, and the "nesting" structure, where a switch-reference clause is located within the controlling clause. Obviously, the availability of the nesting structure is the primary argument for syntactic embedding. However, as stated on pp. 379-380, chains are often structurally ambiguous in the sense that it is impossible to decide, based on their surface shape, whether we are dealing with the linear or nested structure. Maslova concludes, much in line with Longacre (1985), that Yukaghir has no strict formal opposition between coordination and subordination.

This analysis a priori excludes another possibility: that expressions identical on the surface obscure underlying structural distinctions and therefore the ambiguity of chains may only be apparent. There are languages where structural differences in intra-clausal syntax are not accompanied by any overt morphological or word order distinctions. For example, although traditional Altaic studies treat all converbial clauses as subordination (e.g., Ubrjatova \& Litvin 1986), Rudnickaja (1997) argues that Korean converbs in -ko show properties either of subordination or of coordination, depending on how their semantic relation with the finite clause is construed.

The situation in Yukaghir may be similar. The verbal forms involved in chaining are typical instances of what Nedjalkov (1995) refers to as "contextual converbs": the type of semantic relation between the dependent and the main situation is not expressed unambiguously by the verbal form, but is determined contextually. Converbial clauses convey a wide range of semantic relations such as causal, temporal, conditional, concessive, purpose, or manner relations, and are even involved in complementation (pp. 413-414). At least in some of these cases we may well be dealing with subordination. For instance, simultaneous same-subject chains normally have a purpose or manner interpretation and are associated with the embedding nesting structure. 
According to p. 380, structural ambiguity is "an essential property of this strategy of clause linking (rather than an artifact of inadequate tools of syntactic analysis)". However, there is no analysis of the syntactic properties of the chains as such. Coordinated and subordinated structures are known to exhibit different properties with respect to anaphoric binding, gapping, extractions, and scope of quantifiers (van Oirsouw 1987, Goodall 1987, Haspelmath 1995, Johannessen 1998, and others). These tests are not discussed. ${ }^{10}$ In the absence of such a discussion the conclusion about an ambiguity between coordination and subordination seems premature.

I have a few minor terminological disagreements. I am not sure that the socalled Attributive nominal form in $-n \sim-d$ does not have the status of a Genitive case, given that it is not restricted to attributive use, but may serve as the object of a postposition. There are also a few examples where it functions as the object of a non-finite clause. The treatment of case marking of the non-Focus object can be questioned. According to Maslova, with 3rd person subject non-Focus objects take either the Accusative in -gele $\sim-j l e$ or the Instrumental in -le. The Instrumental mostly applies to unmodified nouns, while the Accusative applies to modified nouns and inherently definite objects, such as proper and possessive nouns, as well as personal and demonstrative pronouns. In other words, case marking of the object depends on its deictic status. An alternative solution would be to say that there is no difference in grammatical case but the deictic status of the NP influences the actual form of the case marker. The Accusative has two variants, the "definite" variant -gele $\sim$-jle and the "indefinite" variant $-l e$, while the latter happens to be homonymous with the Instrumental and may ultimately go back to it historically. What we gain with this analysis is a more unified account of case marking and a better conformity to the typological data. Note that a similar solution has been employed elsewhere in the grammar. On Maslova's own account, the Predicative has two forms, -lek and $-k$, and their distribution essentially depends on whether or not the host noun takes a modifier.

Finally, I do not think that the so-called Active verbal attributive form in $j(e)$ and the Passive verbal attributive form in - $m e$ are successfully termed; at least some additional argumentation is needed to show that the difference between them correlates to the active-passive distinction. On the one hand, the form in $-j(e)$ mostly serves to relativize the subject. But it is also employed for

10. A possible reason for this is that such data are difficult to obtain from texts. In her analysis Maslova relied primarily on corpus data, having stressed "the methodological drawbacks of interviews" (p. 16). But no corpus, however large, contains information about all the areas of grammar a linguist might want to explore (cf. Fillmore 1992), and the analyzed Yukaghir corpus is not even particularly large. With respect to the point in question, corpus data could have been usefully augmented by elicited materials. 
relativization of the direct object (examples (281b) and (740)). This function is impossible for active participles. On the other hand, the form in -me relativizes direct objects and locatives. However, there are no apparent reasons to analyze these constructions as passive, especially in the absence of a syntactic passive outside relative clauses. Normally passive participles relativize the passive subject, while the primary participant is encoded as an oblique. In contrast, in relative constructions with $m e$-forms the primary participant is encoded as the subject, as follows from the fact that it triggers agreement. Perhaps it would be more appropriate to term the Passive and the Active attributive forms the Perfective and Imperfective attributive forms, respectively. The tendency is such that the form in -me mostly refers to an event that precedes the main clause event in time, while the event described by the form in $-j(e)$ either follows the main clause event, or coincides with it in time, or has a universal timeless character.

\section{Final remarks}

To conclude, the author of the grammar under review should be given full credit for writing a very thought-provoking description of this intriguing language. Overall, I consider A Grammar of Kolyma Yukaghir an extremely useful piece of work. The book is both informed by modern linguistic scholarship and rich in neatly organized empirical material. It brings to light many interesting new facts about Kolyma Yukaghir and offers clear but sophisticated analyses of its intricate grammatical phenomena. Since any aspect of grammar in a language as little researched as Yukaghir may prove a theoretical challenge, the book is likely to be of great value for theoretical linguists and can be highly recommended to typologists.

Received: 5 November 2003

Revised: 28 September 2004

University of Oxford

Correspondence address: Centre for Linguistics and Philology, Walton Street, Oxford OX1 2HG, United Kingdom; e-mail: irina_a_nikolaeva@yahoo.com

Abbreviations: ABL ablative, ACC accusative, ANR action nominalizer, ATTR attributive, CAUS causative, COM comitative, COP copula, CP connective particle, DAT dative, DETR detransitive, DS different subject, DIM diminutive, FUT future, HORT hortative, IMP imperative, IMPF imperfective, INDF indefinite, INFR inferential, INTR intransitive, INTS intensive, ITR interrogative, ITER iterative, LOC locative, NEG negation, OF object focus, PFV perfective, PL plural, POSs possessive, PRED predicative, RES resultative, RELNR relative nominalizer, SF subject focus, SG singular, ss same subject, SUP supine, TR transitive, $\varnothing$ epenthetic element. 


\section{Irina Nikolaeva}

\section{References}

Allan, Keith (1994). Speech act classification and definition. In Ronald E. Asher (ed.), The Encyclopedia of Language and Linguistics, Volume 8, 4124-4127. Oxford: Pergamon.

Bergelson, Mira B. (2001). Imperative constructions in Bamana. In Xrakovskij (ed.) 2001, 485498.

Brodskaja, Larisa (1988). Složnopodčinennye predloženija v èvenkijskom jazyke. [Subordinate Clauses in Evenki.] Novosibirsk: Nauka.

Bybee, Joan L., Revere D. Perkins, \& William Pagliuca (1994). The Evolution of Grammar: Tense, Aspect and Modality in the Languages of the World. Chicago: University of Chicago Press.

Carlson, Robert (1994). A Grammar of Supyire. Berlin: Mouton de Gruyter.

Čeremisina, Maja (ed.) (1995). Grammatika sovremennogo jakutskogo literaturnogo jazyka: Sintaksis. [A Grammar of Modern Literary Yakut: Syntax.] Novosibirsk: Nauka.

Comrie, Bernard (1992). Focus in Yukagir (Tundra dialect). In Howard I. Aronson (ed.), The Non Slavic Languages of the USSR: Linguistic Studies, 55-70. Chicago: Chicago Linguistic Society.

Dimmendaal, Gerrit J. (1983). The Turkana Language. Dordrecht: Foris.

Du Bois, John W. (1987). The discourse basis of ergativity. Language 63: 805-855.

É. Kiss, Katalin (ed.) (1995). Discourse Configurational Languages. New York: Oxford University Press.

Endo, Fubito (1997). Does Yukaghir really have prefixes? Keizai Riron (The Wakayama Economic Review) 276: 138-149.

Evans, Nicholas (forthcoming). Insubordination and its uses. In Irina Nikolaeva (ed.), All over the Clause: Finiteness. Oxford: Oxford University Press.

Fillmore, Charles J. (1992). 'Corpus linguistics' or 'Computer-aided armchair linguistics'. In Jan Svartvik (ed.), Directions in Corpus Linguistics: Proceedings of Nobel Symposium 82, Stockholm, 4-8 August 1991, 35-60. Berlin: Mouton de Gruyter.

Fortescue, Michael (1996). Grammaticalized focus in Yukaghir: Is it really grammaticalized and is it really focus? In Elisabeth Engberg-Pedersen et al. (eds.), Content, Expression and Structure: Studies in Danish Functional Grammar, 17-38. Amsterdam: Benjamins.

- (1998). Language Relations across Bering Strait: Reappraising the Archaeological and Linguistic Evidence. London: Cassell.

Goodall, Grant T. (1987). Parallel Structures in Syntax: Coordination, Causatives, and Restructuring. Cambridge: Cambridge University Press.

Haspelmath, Martin (1995). The converb as a cross-linguistically valid category. In Haspelmath \& König (eds.) 1995, 1-55.

Haspelmath, Martin \& Ekkehard König (eds.) (1995). Converbs in Cross-linguistic Perspective. Berlin: Mouton de Gruyter.

Jochelson, Waldemar (1898). Obrazcy materialov po izučeniju jukagirskogo jazyka i fol'klora, sobrannye v Jakutskoj èkspedicii. [Samples of materials on Yukaghir language and folklore collected during the Yakut expedition.] Izvestija Imperatorskoj Akademii Nauk 8: 151-177.

- (1900). Materialy po izučeniju jukagirskogo jazyka i fol'klora. [Materials on Yukaghir Language and Folklore.] Sanktpeterburg: Imperatorskaja Akademija Nauk.

- (1905). Essay on the grammar of the Yukaghir language. Annals of the New York Academy of Sciences 16-2. Reprinted in American Anthropologist, New Series 7: 369-424.

Johannessen, Janne Bondi (1998). Coordination. New York: Oxford University Press.

Keenan, Edward L. \& Bernard Comrie (1977). NP accessibility and universal grammar. Linguistic Inquiry 8: 63-100.

Kim, Alan (1988). Preverbal focus position in type XIII languages. In Michael Hammond, Edith Moravcsik, \& Jessica Wirth (eds.), Studies in Syntactic Typology, 148-171. Amsterdam: Benjamins.

Koptjevskaja-Tamm, Maria (1993). Nominalizations. London: Routledge. 
Krejnovič, Eruxim (1979). Jukagirskij jazyk. [The Yukaghir language.] In Jazyki Azii i Afriki, Volume 3: Jazyki drevnej Perednej Azii: Nesemitskie, iberijsko-kavkazskie jazyki, paleoaziatskie jazyki, 348-368. Moskva: Nauka.

- (1982). Issledovanija i materially po jukagirskomu jazyku. [Studies and Materials on the Yukaghir Language.] Leningrad: Nauka.

Longacre, Robert E. (1985). Sentences as combination of clauses. In Timothy Shopen (ed.), Language Typology and Syntactic Description, Volume 2: Complex Constructions, 235-286. Cambridge: Cambridge University Press.

Maslova, Elena (1993). The causative in Yukaghir. In Bernard Comrie \& Maria Polinsky (eds.), Causatives and Transitivity, 271-285. Amsterdam: Benjamins.

- (1997). Yukaghir focus in a typological perspective. Journal of Pragmatics 27: 457-475.

Maslova, Elena (ed.) (2002). Yukaghir Texts. Wiesbaden: Harrassowitz.

Nedjalkov, Vladimir (1995). Some typological parameters of converbs. In Haspelmath \& König (eds.) $1995,97-136$.

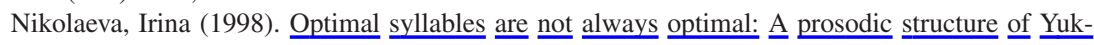
aghir. Lingua 105: 201-229.

Nikolaeva, Irina (ed.) (1989). Fol'klor jukagirov verxnej Kolymy. [Folklore of the Upper Kolyma Yukaghirs.] 2 volumes. Jakutsk: Jakutskij gosudarstvennyj universitet.

- (1997). Yukaghir Texts. (Specimina Sibirica, 13.) Szombathely: Savariae.

Nikolaeva, Irina \& Evgenij Xelimskij (1997). Jukagirskij jazyk. [The Yukaghir language.] In Aleksandr Volodin (ed.), Jazyki mira: Paleoaziatskie jazyki, 155-168. Moskva: Indrik.

Nikolaeva, Irina \& Maria Tolskaya (2001). A Grammar of Udihe. Berlin: Mouton de Gruyter.

Nyikolajeva, Irina (2000). Chrestomathia jucagirica. (Urálisztikai Tanulmányok, 10.) Budapest: Bölcsészettudományi Kar, Eötvös Loránd Tudományegyetem.

Palmer, Frank R. (1986). Mood and Modality. Cambridge: Cambridge University Press.

Potsdam, Eric (1998). Syntactic Issues in the English Imperative. New York: Garland.

Rudnickaja, Elena (1997). Problema altajskogo sočinenija v korejskom jazyke. [The problem of 'Altaic coordination' in Korean.] Voprosy jazykoznanija 1997-6: 89-99.

Sadock, Jerrold M. (1994). Toward a grammatically realistic typology of speech acts. In Savas L. Tsohatzidis (ed.), Foundations of Speech Act Theory: Philosophical and Linguistic Perspectives, 393-406. London: Routledge.

Sadock, Jerrold M. \& Arnold M. Zwicky (1985). Speech act distinctions in syntax. In Timothy Shopen (ed.), Language Typology and Syntactic Description, Volume 1: Clause Structure, 155-196. Cambridge: Cambridge University Press.

Spiridonov, Vasilij \& Irina Nikolaeva (1993). Bukvar' dlja 1 klassa jukagirskix škol (Verxnekolymskij dialekt). [An Alphabet Primer for Grade 1 of Yukaghir Schools (Upper Kolyma Dialect).] Sanktpeterburg: Prosveščenie.

Stachowski, Marek \& Astrid Menz (1998). Yakut. In Lars Johanson \& Éva Á. Csató (eds.), The Turkic Languages, 417-433. London: Routledge.

Szabolcsi, Anna (1994). The noun phrase. In Ferenc Kiefer \& Katalin É. Kiss (eds.), The Syntactic Structure of Hungarian (Syntax and Semantics, 27), 179-274. San Diego: Academic Press.

Ubrjatova, Elizaveta \& Fedor Litvin (eds.) (1986). Strukturnye tipy sintetičeskix polipredikativnyx konstrukcij v jazykax raznyx sistem. [Structural Types of Polypredicative Sentences with Synthetic Verbal Forms in Languages of Different Types.] Novosibirsk: Nauka.

Van Oirsouw, Robert R. (1987). The Syntax of Coordination. London: Croom Helm.

Vincent, Nigel (1993). Head- versus dependent-marking: The case of the clause. In Greville G. Corbett, Norman M. Fraser, \& Scott McGlashan (eds.), Heads in Grammatical Theory, 140 163. Cambridge: Cambridge University Press.

Wetzer, Harrie (1996). The Typology of Adjectival Predication. Berlin: Mouton de Gruyter.

Xrakovskij, Victor (2001). Typology of Imperative Constructions. München: Lincom Europa. 